\title{
Cervical Neuroendocrine Neoplasm
}

National Cancer Institute

\section{Source}

National Cancer Institute. Cervical Neuroendocrine Neoplasm. NCI Thesaurus. Code C128041.

A neuroendocrine neoplasm that arises from the cervix. This category includes low grade neuroendocrine tumor, grade 1 (carcinoid tumor), low grade neuroendocrine tumor, grade 2 (atypical carcinoid tumor), and neuroendocrine carcinoma (small cell and large cell neuroendocrine carcinoma). 